\title{
Antimicrobial susceptibility of Brucella melitensis in Kazakhstan
}

\author{
Alexandr Shevtsov ${ }^{1 *}$ (D), Marat Syzdykov², Andrey Kuznetsov², Alexandr Shustov', Elena Shevtsova', \\ Kalysh Berdimuratova ${ }^{1}$, Kasim Mukanov ${ }^{1}$ and Yerlan Ramankulov ${ }^{1,3}$
}

\begin{abstract}
Background: Kazakhstan belongs to countries with a high level of brucellosis among humans and farm animals. Although antibiotic therapy is the main way to treat acute brucellosis in humans there is still little information on a circulation of the antibiotic-resistant Brucella strains in the Central Eurasia. In this article we describe an occurrence of the drug resistance of Brucella melitensis isolates in Kazakhstan which is among the largest countries of the region.

Methods: Susceptibilities to tetracyclin, gentamycin, doxycyclin, streptomycin and rifampicin were investigated in 329 clinical isolates of Brucella melitensis using E-test method.

Results: All isolates were susceptible to streptomycin, tetracycline and doxycycline. 97.3\% of the Brucella isolates were susceptible to gentamycin, although only $37.4 \%$ of isolates were susceptible to rifampicin. $21.9 \%$ of isolates had intermediate resistance, and $26.4 \%$ of isolates were resistant to this antibacterial drug.

Conclusion: Isolates of Brucella melitensis circulating in Kazakhstan are susceptible to streptomycin, doxicyclin, tetracyclin and gentamycin. At the same time the resistance to rifampicin is widespread, almost half of the isolates were rifampicin-resistant (including the intermediate resistance).
\end{abstract}

Keywords: Brucella melitensis, Antimicrobial susceptibility, Kazakhstan

\section{Background}

Brucellosis remains the most common zoonotic disease with a worldwide incidence estimated at 500 thousand new cases per year [1]. The incidence may be underestimated because of diagnostic errors due to variability in clinical manifestations and underreporting and concealment of data $[2,3]$. Infected terrestrial or marine mammals serve as natural reservoirs and infect people through direct contact or through consumption of the Brucella-contaminated livestock products [4]. Majority of brucellosis cases are recorded in the Mediterranean countries, Southern and Central America, Africa, Asia, Arabian Peninsula, Indian subcontinent, South-Eastern Europe and the Middle East region [1,5]. Among the 12 recognized species in a genus Brucella [6], B. melitensisis is the most common and also the most virulent species which infect humans and causes a debilitating disease $[7,8]$.

* Correspondence: ncbshevtsov@gmail.com

${ }^{1}$ National Center for Biotechnology, Astana, Kazakhstan

Full list of author information is available at the end of the article
Brucellosis is characterized by variability of clinical manifestations from absence of overt symptoms to multi-organ pathologies [9]. Antibiotics are commonly used to treat brucellosis and may suppress replication of the pathogen. One obstacle to the antibiotic therapy is that Brucella can survive in intracellular environments and replicate in macrophages and dendritic cells. For this reason the antibiotics must have intracellular activity. Also the most preferred antibiotics have low toxicity and are suitable for prolonged regiments [10]. The treatment regiments currently recommended by the WHO use a combination of doxycycline and rifampicin for 6 weeks, or doxycycline for 45 days and streptomycin for 21 days.

Brucella spp. actively circulates in humans and domestic animals. During the last 35 years in Kazakhstan an annual incidence rate of the disease in humans varied from 8.5 to 24 cases per 100 thousand (these rates averaged over the whole country) although in some endemic areas the incidence rates exceeded the figures significantly. The most prevalent species in the country in 
humans is B. melitensis [11]. Antibiotics play an important role in the strategy to treat the disease and predominantly determine effectiveness of the treatment. The widely used antibiotics for etiotropic treatment of brucellosis are tetracyclines, trimethoprim/sulfamethoxazole, aminoglycosides, rifampicin and fluoroquinolones $[12,13]$. Low efficacy and frequent relapses after monotherapy led to a transition to a combined treatment regimen in 1986 [14]. However, the combination regimens also have a success below 100\% because of a development of the resistance to the antibiotics [15].

In Kazakhstan the recommended therapeutic scheme is based on the WHO recommendations for the adult population, although the regiments for children and pregnant women may be changed if the drugs appear to be toxic. Despite a high incidence and defiant rate of relapses, still there is little information on the antibiotic resistance among Brucella strains circulating in Kazakhstan.

A high level of bacteriological hazard posed by the live Brucella requires complying to the BSL3 standards which makes an investigation of the antibiotic resistance cumbersome, expensive or even not possible. Nevertheless the data on the antibiotic resistance are important because the resistant Brucella may spread across wide regions [16-18]. In Kazakhstan and the neighboring regions studies of the antibiotic resistance of the circulating Brucella isolates can help to improve the efficacy of treatment.

In this paper we describe the results of a measurement of the antibiotic susceptibility in 329 Brucella melitensis isolates to five commonly used antibiotics.

\section{Methods}

\section{Clinical isolates and characterization of $B$. melitensis}

During 2008-2014 Brucella isolates were collected from patients which were seropositive to a Brucella antigen in a hemagglutination reaction with titers 1:200 and higher. Samples were collected from patients which presented in clinics with symptoms compatible with brucellosis. The blood for Brucella isolation was obtained during standard diagnostic procedures which require a bacteriological isolation of Brucella as a confirmatory test. The blood cultures were produced using the two-phase method proposed by Castaneda $[19,20]$. Primary isolation and a species identification of the Brucella isolates were performed in local hospitals in 11 provinces of Kazakhstan. To confirm the identifications and for further investigation all isolates were further transferred to the Brucellosis laboratory in the Kazakh Scientific Center of Quarantine and Zoonotic Diseases (SC QZD). In total 329 isolates were collected in the SC QZD. The isolates were tested using standard procedures, e.g. $\mathrm{CO}_{2}$ requirement, production of $\mathrm{H}_{2} \mathrm{~S}$, reducing ability for aniline dyes (thionine and basic fuchsine at final concentrations $20-40 \mu \mathrm{g} / \mathrm{ml}$ ), agglutination with specific antisera for $\mathrm{A}$ and $\mathrm{M}$ antigens and susceptibility to lysis with $\mathrm{Tb}$ and Weybridge phages. The species identification was confirmed using the "Bruce-ladder" multiplex PCR [21].

\section{Determination of minimum inhibitory concentrations (MICs)}

MICs of tetracycline, gentamicin, doxycycline, streptomycin and rifampicin were determined using the E-test gradient strips (Biomerieux, Sweden). Suspensions of the bacteria with titers $10^{5}-10^{6} \mathrm{CFU} / \mathrm{ml}$ were inoculated onto surfaces of Brucella agar plates with hemin and vitamin $\mathrm{K}$ (HiMedia Laboratories) and 5\% sheep serum (Sigma-Aldrich). The MICs were determined following $48 \mathrm{~h}$ incubation in ambient air at $37^{\circ} \mathrm{C}$ after placing of the E-test strips in the plates. The reference strains E.coli ATCC 25922 and B. melitensis $16 \mathrm{M}$ were used to control performance of the test.

The MIC thresholds for tetracycline, gentamicin, doxycycline and streptomycin were calculated using the guidelines from the CLSI [22]. Since these guidelines do not provide a classification category for an "intermediate" resistance, all isolates which had the MIC value above the threshold were classified as resistant. Because the threshold for rifampicin has not been established against Brucella other guidelines suitable for slow-growing bacteria (H.influenzae) were used [23]. Isolates having the rifampicin MIC at a value $1.5 \mu \mathrm{g} / \mathrm{mL}$ were not classified as either susceptible or resistant because in the CLSI guidelines this value falls between the categories.

Different measures of the antibiotic effectiveness towards Brucella namely MIC50 and MIC90 were determined. The MIC50 and MIC90 are concentrations of the relevant antibiotics which inhibit growth of $50 \%$ of the isolates or $90 \% \%$ of the isolates, respectively.

\section{Results}

All 329 isolates were found to be a single species B.melitensis by their microbiological characteristics and by a multiplex PCR. Determined ranges of MICs, MIC50 and MIC90 and the assigned classification categories on the susceptibility/resistance are listed in Table 1.

All 329 strains were susceptible to streptomycin, tetracycline and doxycycline and the mentioned antibiotics exhibited high antimicrobial activity. Also $97.3 \%$ of the isolates were susceptible to gentamicin, only $2.7 \%$ were resistant to gentamicin.

A high resistance rate was observed to rifampicin. Only $37.4 \%$ of the isolates were susceptible, $21.9 \%$ showed an intermediate susceptibility and $26.4 \%$ were resistant. Also $14.3 \%$ of the isolates which have $\mathrm{MIC}=$ $1.5 \mu \mathrm{g} / \mathrm{mL}$ were not classified into either category because the CLSI guidelines do not allow to unambiguously assign the category. One striking observation is 
Table 1 Ranges of MICs, MIC50 and MIC90 and antibiotic resistance in 329 B. melitensis isolates

\begin{tabular}{|c|c|c|c|c|c|c|c|c|c|c|c|}
\hline & \multirow{2}{*}{$\begin{array}{l}\text { MICs } \\
\text { range } \\
(\mu \mathrm{g} / \mathrm{mL})\end{array}$} & \multicolumn{3}{|c|}{ Susceptibility $^{a}$ and thresholds $(\mu \mathrm{g} / \mathrm{mL})$} & \multicolumn{2}{|c|}{ MIC50 ( $\mu \mathrm{g} / \mathrm{mL})$} & \multicolumn{2}{|c|}{ MIC90 $(\mu \mathrm{g} / \mathrm{mL})$} & \multicolumn{3}{|c|}{ Classification of isolates, $\mathrm{No}^{1}(\%)^{\mathrm{a}}$} \\
\hline & & $S$ & 1 & $R$ & Value & $\mathrm{No}^{1}$ & Value & $\mathrm{No}^{1}$ & $S$ & I & $R$ \\
\hline rifampicin & $0.38-16$ & $\leq 1$ & 2 & $\geq 4$ & 1.5 & 170 & 8 & 326 & $123(37.4)$ & $72(21.9)$ & $87(26.4)$ \\
\hline rentamicin & $0.5-8$ & $\leq 4$ & - & - & 1 & 188 & 3 & 318 & $320(97.3)$ & - & $9(2.7)$ \\
\hline streptomycin & $0.25-4$ & $\leq 8$ & - & - & 0.75 & 191 & 3 & 327 & $329(100)$ & - & - \\
\hline tetracycline & $0.032-0.5$ & $\leq 1$ & - & - & 0.094 & 165 & 0.25 & 324 & $329(100)$ & - & - \\
\hline doxycycline & $0.023-0.19$ & $\leq 1$ & - & - & 0.047 & 212 & 0.094 & 319 & $329(100)$ & - & - \\
\hline
\end{tabular}

${ }^{a}$ Definitions: $\mathrm{S}$ - susceptible, I- intermediate susceptibility, $\mathrm{R}$ - resistant; ${ }^{1}$ No - number of isolates

that of the nine isolates resistant to gentamycin eight are also resistant to rifampicin.

The MIC90 values for tetracycline and doxycycline were below the respective CLSI thresholds $(25 \%$ and 9.4\% of the thresholds, respectively). For streptomycin the MIC90 was $37.5 \%$ of the threshold and for gentamicin the MIC 90 was of $75 \%$ of the threshold. At the same time, for rifampicin even the MIC50 exceeded the threshold indicating low susceptibility to rifampicin in the circulating Brucella isolates.

Occurrence of resistant isolates differed in samples from various regions of Kazakhstan. All nine isolates which were resistant to gentamicin were collected from the South Kazakhstan. In contrast, the isolates resistant to rifampicin were found almost throughout the country: samples from 7 out of 11 provinces of Kazakhstan contained the rifampicin-resistant isolates. In the particular provinces the occurrence of the rifampicin-resistant isolates is particularly high: $73.3 \%$ in Kyzylorda, $57.1 \%$ in Zhambyl, $52.9 \%$ in Atyrau and $50 \%$ in Karaganda provinces. The same provinces also have the highest prevalence of stains with the intermediate of high resistance to rifampicin (Table 2).

\section{Discussion}

In our study we show that Brucella melitensis isolates in Kazakhstan are susceptible to streptomycin, doxicyclin and tetracyclin, and an absolute majority of the isolates are also susceptible to gentamycin. A very different susceptibility rate was found to rifampicin. The intermediate and full resistance to rifampicin was found in $21.9 \%$ and $26.4 \%$, respectively. This is an important observation because rifampicin is used as the frontline antibiotic in 9 out of 17 therapeutic schemes for brucellosis in Kazakhstan. Also unexpectedly out of nine isolates resistant to gentamicin eight isolates are also resistant to rifampicin.

In a search for a reason for the high occurrence of rifampicin resistance among Brucella isolates in Kazakhstan we compared our data with known geographical patterns of rifampicin resistance for other bacterial pathogens. We speculate that the resistance in Brucella develops in conjunction to a rise in multidrug-resistant tuberculosis (MDR-TB). Kazakhstan is among the top eight countries in the world by an incidence of MDR-TB. Also a frequency of MDR-TB is annually growing among the newly diagnosed TB cases [24]. The highest incidence of MDRTB per 100,000 population is registered in the Atyrau, Kyzylorda, East Kazakhstan, West Kazakhstan, Almaty

Table 2 Geographical distribution of Brucella isolates and their susceptibility/resistance to gentamicin and rifampicin

\begin{tabular}{|c|c|c|c|c|c|c|c|c|c|c|c|}
\hline \multirow[t]{2}{*}{ Region } & \multirow{2}{*}{$\begin{array}{l}\text { Total number } \\
\text { of isolates }(T)\end{array}$} & \multicolumn{4}{|c|}{ Susceptibility to gentamicin } & \multicolumn{6}{|c|}{ Susceptibility to rifampicin } \\
\hline & & $\overline{S(T)}$ & $\mathrm{S}(\%)^{\mathrm{a}}$ & $R(T)$ & $\mathrm{R}(\%)^{\mathrm{a}}$ & $S(T)$ & S (\%) & I (T) & I $(\%)^{a}$ & $R(T)$ & $\mathrm{R}(\%)$ \\
\hline Akmola & 1 & 1 & 100 & 0.0 & 0.0 & 1 & 100.0 & 0.0 & 0.0 & 0.0 & 0.0 \\
\hline Aktibinsk & 7 & 7 & 100 & 0.0 & 0.0 & 1 & 14.3 & 3 & 42.9 & 0.0 & 0.0 \\
\hline Almaty & 91 & 91 & 100 & 0.0 & 0.0 & 39 & 42.9 & 22 & 24.2 & 11 & 12.1 \\
\hline Atyrau & 17 & 17 & 100 & 0.0 & 0.0 & 6 & 35.3 & 2 & 11.8 & 9 & 52.9 \\
\hline East-Kaz. region & 26 & 26 & 100 & 0.0 & 0.0 & 7 & 26.9 & 11 & 42.3 & 5 & 19.2 \\
\hline Zhambyl & 49 & 41 & 83.7 & 8 & 16.3 & 4 & 8.2 & 11 & 22.4 & 28 & 57.1 \\
\hline West-Kaz. region & 26 & 26 & 100.0 & 0.0 & 0.0 & 24 & 92.3 & 2 & 7.7 & 0.0 & 0.0 \\
\hline Karagandy & 16 & 16 & 100.0 & 0.0 & 0.0 & 1 & 6.3 & 5 & 31.3 & 8 & 50.0 \\
\hline Kyzylorda & 30 & 30 & 100.0 & 0.0 & 0.0 & 3 & 10.0 & 4 & 13.3 & 22 & 73.3 \\
\hline North-Kaz. region & 2 & 2 & 100.0 & 0.0 & 0.0 & 0.0 & 0.0 & 1 & 50.0 & 0.0 & 0.0 \\
\hline South-Kaz. region & 64 & 63 & 98.4 & 1 & 1.6 & 37 & 57.8 & 11 & 17.2 & 4 & 6.3 \\
\hline
\end{tabular}

${ }^{\mathrm{a}} \mathrm{S}(\%)=\mathrm{S} / \mathrm{T} \times 100 ; \mathrm{R}(\%)=\mathrm{R} / \mathrm{T} \times 100 ; \mathrm{I}(\%)=\mathrm{I} / \mathrm{T} \times 100$ 
and Zhambyl provinces [25]. The same provinces have the highest occurrence of the resistance to rifampicin.

It was discussed earlier that in regions with prevalent brucellosis there is a potential of developing of MDR-TB because of a treatment of both diseases with the same frontline antibiotics [26]. In reality, the provinces of Kazakhstan with high rates of MDR$\mathrm{TB}$ also have high rates of Brucella resistance to rifampricin [27-29]. Among other countries of the world only Kyrgyzstan (which borders Kazakhstan) also has the high rates of both MDR-TB and brucellosis. Supposedly, the rifampricin treatment of brucellosis is not the only reason for an increase of MDR-TB in the mentioned countries. In Kazakhstan the treatment of brucellosis is carried out only in inpatient clinics thus ensuring compliancy to a treatment regimen. Among possible reasons for the appearance of the antibiotic-resistant Brucella isolates is an uncontrolled use of antibiotics without prescription in a population to treat influenza-like symptoms and also uncontrolled distribution of the antibiotics by local sellers (this practice was stopped by an issuance of novel regulations on sells of the antibiotics in 2016). Data on a previous treatment of $\mathrm{TB}$ in the population from which Brucella isolates were obtained are not available.

Our study underscores a need in a comprehensive and regular monitoring of the antibiotic resistance in the circulating Brucella isolates. Given that brucellosis is a zoonotic disease there is a need to expand the studies to include the isolates from animals. The data presented in this article will help in understanding and ensuring of an adequate control on the brucellosis in the Central Eurasia.

\section{Conclusion}

This study shows that $48 \%$ of isolates of Brucella mellitensis collected from humans in Kazakhstan are resistant to rifampicin. The data reported can be used to optimize the therapy regiments.

\section{Abbreviations \\ ATCC: American type culture collection; CFU: Colony forming unit; CLSI: Clinical \& Laboratory Standards Institute; MIC: Minimum inhibitory concentration; PCR: Polymerase chain reaction; SC QZD: Kazakh Scientific Center of the Quarantine and Zoonotic Diseases}

\section{Acknowledgements}

We would like to thank Ranjan Gupta, Ph.D. and Nancy Touchette, Ph.D. for helping to preparing the manuscript.

\section{Funding}

This work was supported by funding received from the Ministry of Education and Science of the Republic of Kazakhstan, grant no. 1520/GF4.

Availability of data and materials

Please contact corresponding author for data requests.

\section{Authors' contributions}

AShe, MS, AK and ER were involved in the conception and design of the study. MS, AK, and KB performed the identification and characterisation of isolates. AShe, AShu, AK, ESh and KM were involved in the analysis and interpretation of the data. All authors read and approved the final manuscript.

Ethics approval and consent to participate

Not applicable.

\section{Consent for publication}

Not applicable.

\section{Competing interests}

The authors declare that they have no competing interests.

\section{Publisher's Note}

Springer Nature remains neutral with regard to jurisdictional claims in published maps and institutional affiliations.

\section{Author details}

${ }^{1}$ National Center for Biotechnology, Astana, Kazakhstan. ${ }^{2}$ Kazakh Scientific Center of Quarantine and Zoonotic Diseases named by Masgut Aykimbayev, Almaty, Kazakhstan. ${ }^{3}$ School of Science and Technology Nazarbayev University, Astana, Kazakhstan.

Received: 23 October 2017 Accepted: 18 December 2017

Published online: 28 December 2017

\section{References}

1. Pappas G, Papadimitriou P, Akritidis N, Christou L, Tsianos EV. The new global map of human brucellosis. Lancet Infect Dis. 2006;6(2):91-9.

2. Mantur BG, Amarnath SK, Shinde RS. Review of clinical and laboratory features of human brucellosis. Indian J Med Microbiol. 2007;25(3):188-202.

3. Durusoy R, Karababa AO. Completeness of hepatitis, brucellosis, syphilis, measles and HIV/AIDS surveillance in Izmir, Turkey. BMC Public Health. 2010:10:71.

4. Ravanel N, Gestin B, Maurin M. In vitro selection of fluoroquinolone resistance in Brucella melitensis. Int J Antimicrob Agents. 2009;34(1):76-81.

5. Nicoletti P. Brucellosis: past, present and future. Prilozi. 2010;31(1):21-32.

6. Scholz HC, Revilla-Fernandez S, Al Dahouk S, Hammerl JA, Zygmunt MS, Cloeckaert A, Koylass M, Whatmore AM, Blom J, Vergnaud G, et al. Brucella vulpis sp. nov., isolated from mandibular lymph nodes of red foxes (Vulpes Vulpes). Int J Syst Evol Microbiol. 2016;66(5):2090-8.

7. Eschenbrenner M, Wagner MA, Horn TA, Kraycer JA, Mujer CV, Hagius $S$, Elzer P, DelVecchio VG. Comparative proteome analysis of Brucella melitensis vaccine strain rev 1 and a virulent strain, 16M. J Bacteriol. 2002; 184(18):4962-70.

8. Diaz Aparicio E. Epidemiology of brucellosis in domestic animals caused by Brucella melitensis, Brucella suis and Brucella abortus. Rev Sci Tech. 2013; 32(1):43-51. 53-60

9. Galinska EM, Zagorski J. Brucellosis in humans - etiology, diagnostics, clinical forms. Ann Agr Env Med. 2013;20(2):233-8.

10. Yousefi-Nooraie R, Mortaz-Hejri S, Mehrani M, Sadeghipour P. Antibiotics for treating human brucellosis. Cochrane Database Syst Rev. 2012;10:CD007179.

11. Shevtsova E, Shevtsov A, Mukanov K, Filipenko M, Kamalova D, Sytnik I, Syzdykov M, Kuznetsov A, Akhmetova A, Zharova M, et al. Epidemiology of brucellosis and genetic diversity of Brucella abortus in Kazakhstan. PLoS One. 2016:11(12):e0167496.

12. Saltoglu N, Tasova Y, Inal AS, Seki T, Aksu HS. Efficacy of rifampicin plus doxycycline versus rifampicin plus quinolone in the treatment of brucellosis. Saudi Med J. 2002;23(8):921-4.

13. Geyik MF, Gur A, Nas K, Cevik R, Sarac J, Dikici B, Ayaz C. Musculoskeletal involvement of brucellosis in different age groups: a study of 195 cases. Swiss Med Wkly. 2002;132(7-8):98-105.

14. Corbel MJ. Brucellosis in humans and animals. Geneva: World Health Organization; 2006.

15. Ariza J, Gudiol F, Pallares R, Viladrich PF, Rufi G, Corredoira J, Miravitlles MR. Treatment of human brucellosis with Doxycycline plus Rifampin or Doxycycline plus streptomycin - a randomized, double-blind-study. Ann Intern Med. 1992;117(1):25-30. 
16. Bayram Y, Korkoca H, Aypak C, Parlak M, Cikman A, Kilic S, Berktas M Antimicrobial susceptibilities of Brucella isolates from various clinical specimens. Int J Med Sci. 2011;8(3):198-202.

17. Kinsara A, Al-Mowallad A, Osoba AO. Increasing resistance of Brucellae to co-trimoxazole. Antimicrob Agents Chemother. 1999;43(6):1531.

18. De Rautlin de la Roy YM, Grignon B, Grollier G, Coindreau MF, BecqGiraudon B. Rifampicin resistance in a strain of Brucella melitensis after treatment with doxycycline and rifampicin. J Antimicrob Chemother. 1986;18(5):648-9.

19. Castaneda MR. A practical method for routine blood cultures in brucellosis. Proc Soc Exp Biol Med. 1947;64(1):114.

20. Yagupsky P. Detection of Brucellae in blood cultures. J Clin Microbiol. 1999; 37(11):3437-42

21. Lopez-Goni I, Garcia-Yoldi D, Marin CM, de Miguel MJ, Munoz PM, Blasco JM, Jacques I, Grayon M, Cloeckaert A, Ferreira AC, et al. Evaluation of a multiplex PCR assay (Bruce-ladder) for molecular typing of all Brucella species, including the vaccine strains. J Clin Microbiol. 2008;46(10):3484-7.

22. Jorgensen JH, Hindler JA, Bernard K. Methods of antimicrobial dilution and disk susceptibility testing of infrequently isolated or fastidious bacteria. Approved guidelines - second edition, vol. 30. Wayne, PA: Clinical and Laboratory Standard Institute; 2010.

23. CLSI. Performance standard for antimicrobial susceptibility testing: twentyfourth informational supplement.CLSI document M100-S24, vol. 34. Wayne, PA: Clinical and Laboratory Standard Institute; 2014.

24. Organization WH. Global tuberculosis report 2013. Geneva: World Health Organization; 2013

25. Terlikbayeva A, Hermosilla S, Galea S, Schluger N, Yegeubayeva S, Abildayev T, Muminov T, Akiyanova F, Bartkowiak L, Zhumadilov Z, et al. Tuberculosis in Kazakhstan: analysis of risk determinants in national surveillance data. BMC Infect Dis. 2012;12:262.

26. Ariza J, Bosilkovski M, Cascio A, Colmenero JD, Corbel MJ, Falagas ME, Memish ZA, Roushan MR, Rubinstein E, Sipsas NV, et al. Perspectives for the treatment of brucellosis in the 21st century: the loannina recommendations. PLoS Med. 2007;4(12):e317.

27. Barbosa Pauletti R, Reinato Stynen AP, Pinto da Silva Mol J, Seles Dorneles EM, Alves TM, de Sousa Moura Souto M, Minharro S, Heinemann MB, Lage AP. Reduced susceptibility to Rifampicin and resistance to multiple antimicrobial agents among Brucella abortus isolates from cattle in Brazil. PLoS One. 2015;10(7):e0132532.

28. Denk A, Demirdag K, Kalkan A, Ozden M, Cetinkaya B, Kilic SS. In vitro activity of Brucella melitensis isolates to various antimicrobials in Turkey. Infect Dis (Lond). 2015:47(6):364-9.

29. Abdel-Maksoud M, House B, Wasfy M, Abdel-Rahman B, Pimentel G, Roushdy G, Dueger E. In vitro antibiotic susceptibility testing of Brucella isolates from Egypt between 1999 and 2007 and evidence of probable rifampin resistance. Ann Clin Microbiol Antimicrob. 2012:11:24.

\section{Submit your next manuscript to BioMed Central and we will help you at every step:}

- We accept pre-submission inquiries

- Our selector tool helps you to find the most relevant journal

- We provide round the clock customer support

- Convenient online submission

- Thorough peer review

- Inclusion in PubMed and all major indexing services

- Maximum visibility for your research

Submit your manuscript at www.biomedcentral.com/submit

) Biomed Central 